\title{
Study of Methods for Cogging Torque Reduction in Permanent Magnet Machines
}

\author{
Dianning $\mathrm{Wu}^{1, \mathrm{a}}, \quad$ Zhongyuan Yang ${ }^{2, \mathrm{~b}}$ \\ ${ }^{1}$ Department of Electrical Engineering, Qingdao University, Qingdao,266071,China \\ ${ }^{2}$ Department of State grid SHANDONG electric power maintenance company,Jinan, 250000, China \\ aemail: 578042748@qq.com, bemail: yangzhongyuan0505@163.com
}

Keywords: permanent magnet(PM) machine; cogging torque; reduction method; finite-element method.

\begin{abstract}
To propose the methods for cogging torque reduction in permanent magnet machines, theoretical reasons of cogging torque are studied in this paper and the qualitative analysis is performed before quantitative calculation with finite-element method. And the effects of slot opening widths, unequal thickness magnets as well as pole-arc factors on cogging torque in PM machines are then analyzed with finite-element method. Finally, the methods to reduce cogging torque in PM machines are summarized, which demonstrate that with proper methods the cogging torque can be significantly decreased.
\end{abstract}

\section{Introduction}

Permanent machines have been widely used compared with conventional machines due to their significant advantages such as the simple structure, reliable operation, small volume and less dissipation $^{[1-4]}$. However, the inevitably cogging torque caused by the interaction between magnets and the slotted stator core would lead to the torque pulsation, vibration and noise, which even affects the control accuracy of the system.

Cogging torque is the specific problem in PM machines, which is also the crucial problem to be considered and solved in design and manufacture of high performance PM machines. There have existed many documents illustrating methods for cogging torque reduction, such as auxiliary slots, suitable selection of the teeth width ratio, proper pole-arc coefficient, optimized magnetism charging, enlarged air-gap, non-uniform distribution of stator slots and skewed slots, etc $\mathrm{al}^{[5-9]}$. But one thing worth noting is that many of these methods achieve the goal of cogging torque reduction under the cost of both the reduced electromagnetic torque and the complexity of optimal design for PM machines. In addition, the economic requirement also limits the application of these methods in practical. Since the same method has unequal effects on PM machines with different structures and parameters, proper methods for effectively cogging torque reduction should be applied with specific structure taken into consideration.

This paper choose a surface-mounted PM machine with 4 poles and 36 slots as the prototype to analyze the effects of slot opening width, unequal magnet thickness and the pole-arc coefficient on cogging torque in PM machines.

\section{Causes of Cogging Torque}

Cogging torque arises from the interaction between magnets and slots in PM machines without current in windings. And no cogging torque is found in smooth core machines. The relative movement between stator and rotor as well as the tooth effect causes the uneven air-gap permeance, which changed the energy storage in air-gap magnetic field and creates the cogging torque. Cogging torque $T_{c o g}$ is defined as the negative derivative of the magnetic energy $W$ to the relative position angle $\alpha$, as shown in Eqn. (1). The position angle $\alpha$ is defined as the angle between central lines of one teeth and the magnet as shown in Fig. 1. 


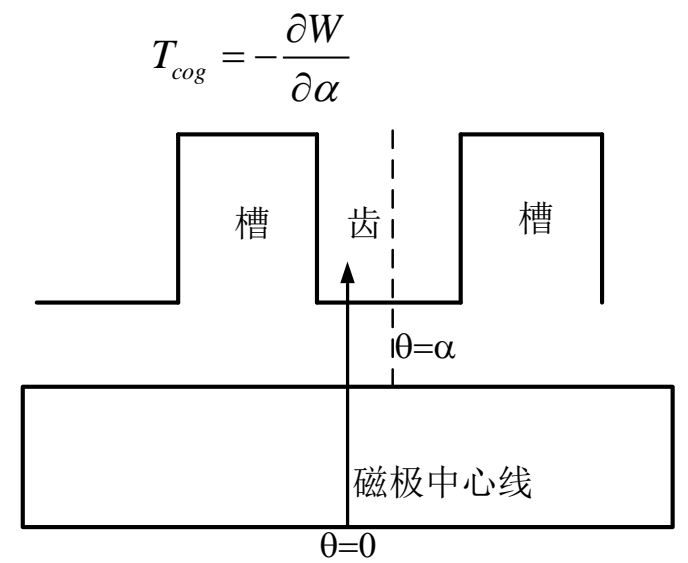

Fig. 1 The diagram of position angle $\alpha$ in cogging torque calculation

Before analytic calculation, following assumptions are prompted:

(1) The magnetic permeability of stator core is infinitely great, and the stacking factor is 1 , with magnetic hysteresis and eddy current ignored.

(2) The magnets are uniformly charged magnetism, symmetric and have the same shape.

(3) The magnetic permeability of magnets and air are the same with the permeability of vacuum.

(4) The end winding effect is neglected.

(5) The effect of slots on magnetic field is calculated with Carter coefficient.

(6) The central line of magnet is aligned with that of slot.

Based on the above assumptions, the energy of magnetic field in PM machines is approximately equal to the sum of energies in air-gap and magnet, as shown in Eqn. (2):

$$
W \approx W_{\text {airgap }}+W_{P M}=\frac{1}{2 \mu_{0}} \int_{V} B^{2} d V
$$

The distribution of air-gap magnetic density $B$ around the armature surface can be approximately expressed as

$$
B(\theta, \alpha)=B_{r}(\theta) \frac{h_{m}}{h_{m}+\delta(\theta, \alpha)}
$$

Substitute Eqn. (2) into Eqn. (3), the magnetic field energy in PM machine is of the form:

$$
W=\frac{1}{2 \mu_{0}} \int_{V} B_{r}^{2}(\theta)\left[\frac{h_{m}}{h_{m}+\delta(\theta, \alpha)}\right]^{2} \mathrm{~d} V
$$

With $B_{r}{ }^{2}(\theta)$ and $\left[\frac{h_{m}}{h_{m}+\delta(\theta, \alpha)}\right]^{2}$ Fourier decomposed they can be derived as follows

$$
\begin{aligned}
& B_{r}^{2}(\theta)=B_{r 0}+\sum_{n=1} B_{r n} \cos 2 n p \theta \\
& {\left[\frac{h_{m}}{h_{m}+\delta}\right]^{2}=G_{0}+\sum_{n=1}^{\infty} G_{n} \cos n z \theta}
\end{aligned}
$$

Substitute Eqn. (5) and Eqn. (6) into Eqn. (4) and we can get the cogging torque according to Eqn. (1) as

$$
T_{c o g}(\alpha)=\frac{\pi z L_{a}}{4 \mu_{0}}\left(R_{2}^{2}-R_{1}^{2}\right) \sum_{n=1}^{\infty} n G_{n} B_{r \frac{n z}{2 p}} \sin n z \alpha_{p}
$$

Both $B_{r}^{2}(\theta)$ and $\left[\frac{h_{m}}{h_{m}+\delta(\theta, \alpha)}\right]^{2}$ are supposed to have effects on cogging torque, but not every Fourier component of them does work. There are only the $n z / 2 p$ Fourier components of $B_{r}{ }^{2}(\theta)$ and 
the $n$ Fourier components of $\left[\frac{h_{m}}{h_{m}+\delta(\theta, \alpha)}\right]^{2}$ that affect cogging torque, which means that the reduction of $B_{r(n z / 2 p)}$ and $G_{n}$ leads to a less cogging torque.

\section{Methods to reduce cogging.}

This paper chooses a 4-pole 36-slot surface mounted permanent magnet machine as the prototype, with its parameters shown in Table. 1.The sectional view of the prototype is shown as Fig. 2. All the attempts are simulated with the finite-element methods.

Table. 1 parameters of prototype

\begin{tabular}{|c|c|c|c|}
\hline $\begin{array}{c}\text { Outer stator } \\
\text { radius/mm }\end{array}$ & $\begin{array}{c}\text { Inner stator } \\
\text { radius } / \mathrm{mm}\end{array}$ & $\begin{array}{c}\text { Outer rotor } \\
\text { radius } / \mathrm{mm}\end{array}$ & $\begin{array}{c}\text { Air-gap } \\
\text { length/mm }\end{array}$ \\
\hline 175 & 101 & 99 & 1 \\
\hline $\begin{array}{c}\text { Coercive } \\
\text { force } / \mathrm{kA} \cdot \mathrm{m}^{-1}\end{array}$ & $\begin{array}{c}\text { Magnet } \\
\text { thickness } / \mathrm{mm}\end{array}$ & $\begin{array}{c}\text { Core } \\
\text { length } / \mathrm{mm}\end{array}$ & Pole-pairs \\
\hline 820 & 12 & 129 & 2 \\
\hline
\end{tabular}

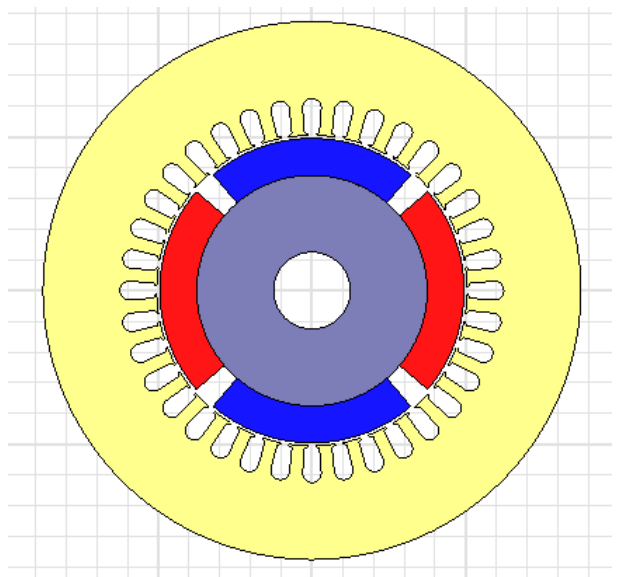

Fig. 2 Sectional view of 4-pole 36-slot permanent magnet machine

Optimization of pole-arc coefficient. It can be seen from Eqn. (7) that only the $n z / 2 p$ Fourier components of $B_{r}^{2}(\theta)$ has influence on the cogging torque, which means that once the numbers of pole-pairs and slots are determined, the Fourier component of $B_{r}^{2}(\theta)$ will be derived. From analysis we know that the Fourier components of $B_{r}{ }^{2}(\theta)$ are related to pole-arc coefficient. When the number of stator slots is 36 , cogging torque is only associated with the $9 k$ ( $k$ is an integral number) Fourier components of $B_{r}{ }^{2}(\theta)$. And once the condition $k=n z / 2 p$ is satisfied, cogging torque can be reduced greatly. Therefore, a proper pole-arc coefficient leads to the less $B_{r 9}, B_{r 18}$ and $B_{r 27}$. As to the prototype, when the pole-arc coefficient is $8 / 9, B_{r 9}$ is equal to 0 and the cogging torque would be much less. The waveforms of different pole-arc coefficients can be seen in Fig. 3.

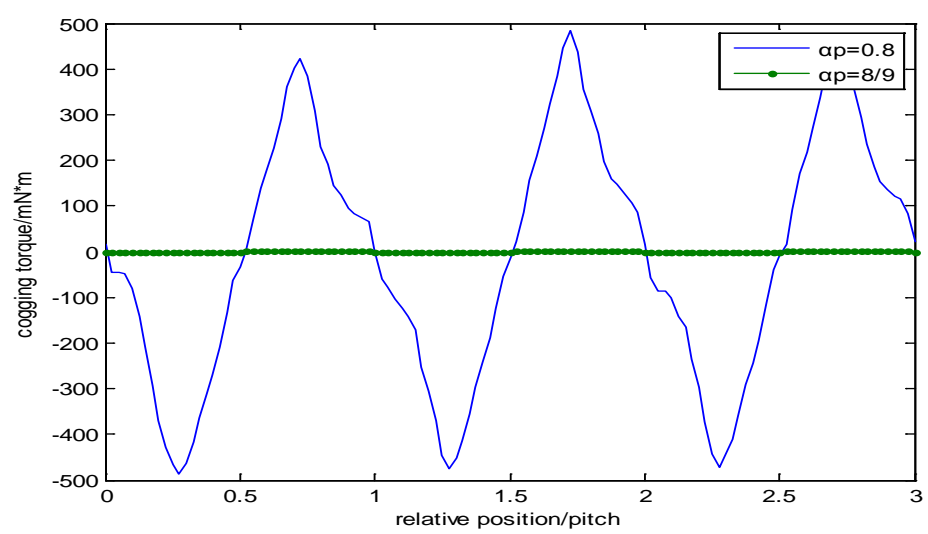

Fig. 3 Waveforms of cogging torques with different pole-arc coefficients 
Reduction of slot opening width. Cogging torque is affected by $G_{n}$, which is related to the slot opening width. The method to reduce the slot opening width offers an advantage that it does not need to change the structure, because only the change of physical dimensions can decrease the cogging torque. Fig. 4 shows the waveforms of cogging torque with slot opening widths as $2.5 \mathrm{~mm}$, $2.2 \mathrm{~mm}, 2.0 \mathrm{~mm}$ and $1.8 \mathrm{~mm}$ separately. From Fig. 4 we can see that a less slot opening width leads to a less cogging torque. But the slot opening width can not be designed too less because a narrow slot opening width is difficult for winding inserting.

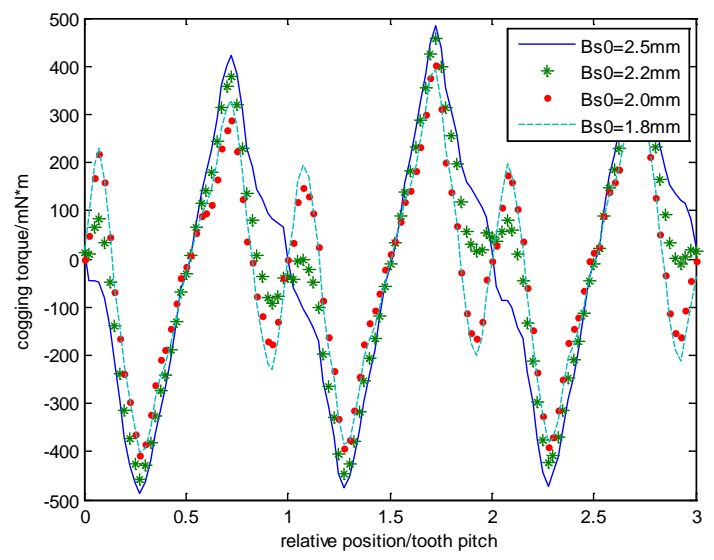

Fig.4 Waveform of cogging torque with different slot opening widths

Unequal thickness of magnetic pole. As shown in Fig. 5, the center of outer arc of magnetic pole with unequal thickness is at $O$, and that of the inner arc is at $O$ '. The thickness of magnetic pole $h^{\prime}{ }_{m}(\theta)$ and the air-gap length $\delta^{\prime}(\theta)$ vary with the position angle. The eccentricity $h$ is the distance between $O$ and $O$ '. Different $h$ determines different distribution of radial component of air-gap magnetic density. The radial component of air-gap magnetic density with no eccentricity is of the form

$$
B(\theta)=B_{r}(\theta) \frac{h_{m}}{h_{m}+\delta(\theta)}
$$

The radial component of air-gap magnetic density with eccentricity is of the form

$$
B^{\prime}(\theta)=B_{r}(\theta) \frac{h_{m}{ }^{\prime}(\theta)}{h_{m}{ }^{\prime}(\theta)+\delta^{\prime}(\theta)}=B_{r}{ }^{\prime}(\theta) \frac{h_{m}}{h_{m}+\delta(\theta)}
$$

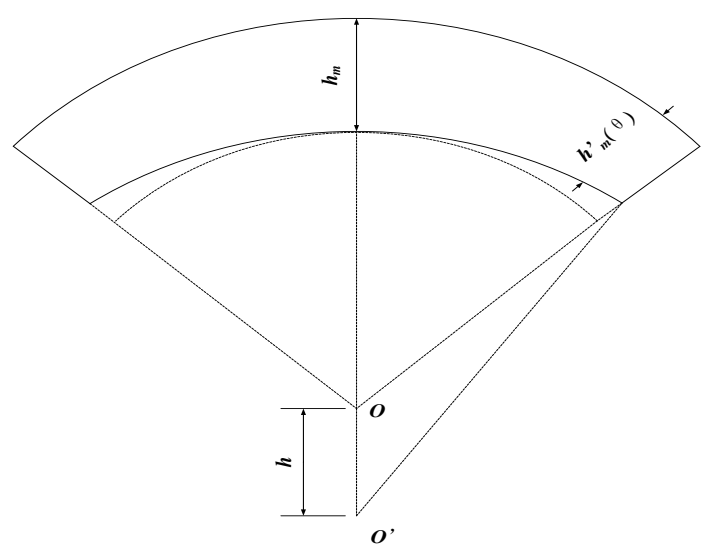

Fig. 5 Magnetic pole with unequal thickness

$B_{r(n z / 2 p)}$ is derived from Fourier decomposition of $B_{r}{ }^{2}(\theta)$, and the cogging torque can be analyzed with Eqn. (9). The waveforms of cogging torque of magnetic poles with different eccentricities as $7 \mathrm{~mm}$ and $12 \mathrm{~mm}$ are shown in Fig. 6, which indicates that a larger eccentricity leads to a less cogging torque. 


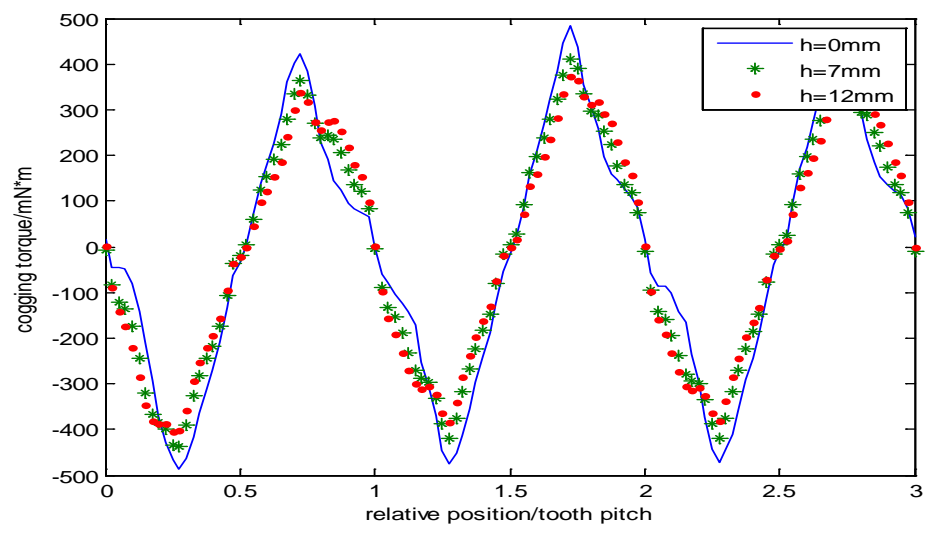

Fig. 6 Waveforms of cogging torque with different eccentricities

\section{Conclusion}

The reason and theoretical expression for cogging torque in permanent magnet machines is studied in this paper. And the effects of different pole-arc coefficients, different slot opening widths and different thicknesses of magnetic poles on cogging torque in prototype are also quantitatively calculated with finite-element method. The analysis indicates that cogging torque relates to the $n z / 2 p$ Fourier components of the square of the remanent magnetism, which offers the theoretical foundation of cogging torque reduction with proper pole-arc coefficient. With a less slot opening width or larger eccentricity of unequal thickness magnetic pole would both decrease cogging torque. The methods for cogging torque reduction in this paper can improve the stability of low speed operation remarkably and expend the application for permanent magnet machines.

\section{Reference}

[1] Tang Renyuan: Modern Permanent Magnet Machines Theory and Design [M]. Beijing: China Machine Press, 1997.

[2] Wang Xiuhe: Permanent Magnet Machine. Beijing: China Electric Power Press, 2007.

[3] Chen Junfeng: Permanent Magnet Machine. Beijing: China Machine Press, 1983.

[4] Li Zhongming, Liu Weiguo, Liu Jinglin: Rare-Earth Permanent Magnet Machines. Beijing: National Defense Industry Press, 1997.

[5] Wang Xiuhe, Yang Yubo, Ding Tingting, Zhu Changqing, Wang Daohan: The Method for reducing Cogging Torque by Suitable Selection of Pole-arc Coefficient in Solid-Rotor PM Synchronous Motors. Proceedings of the CSEE, vol. 25 No. 15 Aug. 2005.

[6] Xie Fang, Huang Shoudao, Liu Ting: Analysis and Research on the Cogging Torque of Interior Permanent Magnet Machines. Small \& Special Electrical Machines, 1004-7018(2009)11-0011-04.

[7] Luo Honghao, Liao Zili: Harmonic Analysis and Minimization of Cogging Torque in Permanent Magnet Motors. Electric Machines and Control, Vol. 14 No. 4 Apr. 2010.

[8] Dong Shizhen, Ma Jun, Shen Jianxin: Optimal Slot Opening Design for Cogging Torque Reduction of Permanent Motor. Micromotors, 1001-6848(2007) 12-0001-03.

[9] Ji Pi, Wang Xiuhe, Wang Daohan, Yang Yubo: Study of Cogging Torque in Surface-Mounted Permanent Magnet Motors with Static Eccentricity. Proceedings of CSEE, vol. 24 No. 9 Sep. 2004. 